LAWRENCE LIVERMORE N A T IO N A L LABORATORY

\title{
Synthesis and Characterization of a Nanocrystalline Thoria Aerogel
}

R. A. Reibold, J. F. Poco, T. F. Baumann, R. L. Simpson, J. H. Satcher, Jr

February 6, 2004

Journal of Non-Crystalline Solids 
This document was prepared as an account of work sponsored by an agency of the United States Government. Neither the United States Government nor the University of California nor any of their employees, makes any warranty, express or implied, or assumes any legal liability or responsibility for the accuracy, completeness, or usefulness of any information, apparatus, product, or process disclosed, or represents that its use would not infringe privately owned rights. Reference herein to any specific commercial product, process, or service by trade name, trademark, manufacturer, or otherwise, does not necessarily constitute or imply its endorsement, recommendation, or favoring by the United States Government or the University of California. The views and opinions of authors expressed herein do not necessarily state or reflect those of the United States Government or the University of California, and shall not be used for advertising or product endorsement purposes. 


\title{
Synthesis and Characterization of a Nanocrystalline Thoria Aerogel
}

Robert A. Reibold, John F. Poco, Theodore F. Baumann, Randall L. Simpson and Joe H. Satcher, Jr.

Lawrence Livermore National Laboratory, Chemistry and Material Science Directorate, P.O. Box 808 L-092, Livermore, CA 94550, USA

\begin{abstract}
We report the synthesis and characterization for the first example of a low-density nanocrystalline thoria aerogel. The monolithic aerogels were prepared through the solgel polymerization of hydrated thorium nitrate in ethanol using ammonium hydroxide and propylene oxide as gelation initiators. The dried $\mathrm{ThO}_{2}$ aerogel was characterized by high-resolution transmission electron microscopy (HRTEM) and nitrogen adsorption/desorption analyses. The aerogel network was determined to be composed of spherical primary particles with features in the 5-20 $\mathrm{nm}$ range. These particles were also determined to be highly crystalline as evidenced by the higher magnification TEM examination. The thoria aerogel possesses high surface area $\left(120 \mathrm{~m}^{2} / \mathrm{g}\right)$ and pore diameters in the micro- and mesoporous range.
\end{abstract}

PACS: 81.20.Fw; 82.33.Ln 


\section{Introduction}

Thorium oxide, $\mathrm{ThO}_{2}$, has long been an important component in the nuclear industry [1-5] and has more recently found utility in the design of a variety of new materials, including catalysts [6-9], electrodes [10-12], fuel cell electrolytes [13] and sensors [14]. For each of these applications, one must be able to reliably control composition, porosity and densities of the thoria products. The sol-gel process is an excellent method for controlling the properties of metal oxide materials on the nanometer scale [15]. Historically, the sol-gel method utilizes metal alkoxides precursors that readily undergo catalyzed hydrolysis and condensation reactions to form a metal oxide gel, comprised of particles with nanoscale dimensions $(1-100 \mathrm{~nm})$. This synthetic route has been used to produce a variety of metal oxide materials with a range of physical properties [16]. Alkoxides of actinides, however, are not commercially available and are generally difficult to prepare and handle, thus precluding their use in the synthesis of solgel materials. Preparation of thoria materials typically involves the aqueous precipitation of thorium oxalate followed by high temperature calcination. This approach allows for little control over the bulk properties of the resultant materials.

We have recently developed a new sol-gel technique for the synthesis of transition and main-group metal oxide aerogels, xerogels and nanocomposites $[17,18]$. This new method involves the use of epoxides as gelation initiators in the preparation of sol-gel materials. One of the advantages to this technique is that it utilizes simple metal salts (i.e. metal nitrates or halides) as precursors in the sol-gel reaction, eliminating the need for metal alkoxides. As a result, novel nanostructured materials with unique compositions can be prepared. Using this approach, we recently reported here first 
example of a low-density urania $\left(\mathrm{UO}_{3}\right)$ aerogel [19]. In the work presented here, the synthesis of a nanocrystalline thoria aerogel using a modification of the epoxide method will be discussed. The microstructure and porosity of the thoria aerogel will also be presented.

\section{Experimental}

Thorium nitrate tetrahydrate, $\mathrm{Th}\left(\mathrm{NO}_{3}\right)_{4} \bullet 4 \mathrm{H}_{2} \mathrm{O}$ (Alfa-Aesar), propylene oxide (99\%, Aldrich), absolute ethanol (Aaper Alcohol), ammonium hydroxide (Aldrich) and acetone (Aldrich) were used as received. In a typical synthesis, thorium nitrate tetrahydrate $(8.2 \mathrm{~g}, 14 \mathrm{mmol})$ was dissolved in absolute ethanol $(15 \mathrm{~mL})$ and, to this solution, ammonium hydroxide $(2.25 \mathrm{~mL})$ was slowly added dropwise. With each drop of ammonium hydroxide, a white precipitate formed and then redissolved. This precipitate must be allowed to dissolve before the next drop of $\mathrm{NH}_{4} \mathrm{OH}$ can be added. After addition of the ammonium hydroxide, propylene oxide $(5.7 \mathrm{~g}, 98 \mathrm{mmol})$ was added to the solution. The reaction mixture was stirred for $0.5 \mathrm{~h}$, then transferred to glass molds and the solutions were allowed to gel at RT for $72 \mathrm{~h}$, during which time, translucent white alcogels formed. The monoliths were then soaked in an acetone bath for 3 days to remove reaction by-products and unreacted starting material.

\subsection{Gel processing conditions}

The thoria alcogels were processed in a Polaron ${ }^{\mathrm{TM}}$ critical point extractor. The acetone in the pores of the wet gels was exchanged with liquid $\mathrm{CO}_{2}$ for 3-4 days, after which time, the temperature was ramped up to $\sim 45^{\circ} \mathrm{C}$, while maintaining a pressure of $\sim 100$ bars. The autoclave was then depressurized at a rate of $\sim 7 \mathrm{bar} / \mathrm{h}$, affording the aerogels as opaque white monoliths. 


\subsection{Physical Characterization}

The bulk density of the thoria aerogel sample was determined by measuring the dimensions and mass of the monolithic sample. High-resolution transmission electron microscopy (HRTEM) of the thoria aerogels was performed on a Philips CM300FEG operating at $300 \mathrm{keV}$ using zero loss energy filtering with a Gatan energy imaging filter (GIF) to remove inelastic scattering. The images were taken under BF (bright field) conditions and slightly defocused to increase contrast. The images were also recorded on a $2 \mathrm{~K} \times 2 \mathrm{~K}$ CCD camera attached to the GIF. Surface area determination as well as pore volume and size analysis were performed by BET (Brunauer-Emmett-Teller) and BJH (Barrett-Joyner-Halenda) methods using an ASAP 2000 surface area analyzer (Micromeritic Instrument Corporation). Samples of approximately $0.1 \mathrm{~g}$ were heated to $200^{\circ} \mathrm{C}$ under vacuum $\left(10^{-5}\right)$ Torr) for at least $24 \mathrm{~h}$ to remove all adsorbed species. Nitrogen adsorption data were taken at five relative pressures from 0.05 to 0.20 at $77 \mathrm{~K}$, to calculate the surface area by BET theory [20].

\section{Results}

We have previously demonstrated the utility of epoxides in the synthesis of a variety of metal oxide aerogels and xerogels [17-19]. In the work presented here, lowdensity $\mathrm{ThO}_{2}$ aerogels were prepared through the sol-gel polymerization of hydrated thorium nitrate in ethanol using both ammonium hydroxide and propylene oxide as gelation initiators. Unlike our work with other metal oxide systems, attempts to prepare thoria alcogels from hydrated thorium nitrate using only propylene oxide as a catalyst were unsuccessful. Addition of one molar equivalent of ammonium hydroxide to the thorium nitrate solution followed by seven equivalents of propylene oxide was necessary 
for the formation of the thoria alcogel. These values represent the minimum amount of each initiator required to form the thoria alcogel, as determined from experiments where different amounts of ammonium hydroxide and epoxide were used in the sol-gel reaction. The $\mathrm{ThO}_{2}$ alcogels were dried under supercritical conditions with liquid $\mathrm{CO}_{2}$ to produce $\mathrm{ThO}_{2}$ monoliths. Typical densities of the dried $\mathrm{ThO}_{2}$ aerogels were 0.1 to $0.2 \mathrm{~g} / \mathrm{cm}^{3}$. Attempts to produce higher density monoliths by this method were largely unsuccessful.

High-resolution transmission electron microscopy (HRTEM) was utilized to examine the morphology of the $\mathrm{ThO}_{2}$ aerogels (Figure 1). The low magnification micrograph reveals the expanded treelike structure of the aerogel (Figure 1a). Qualitatively, the material appears to be comprised of interconnected thoria particles that define cavities of mesoporous $(20-50 \mathrm{~nm})$ dimensions. The higher magnification image (Figure 1b) provides more details about the size, shape and connectivity of the clusters that make up the thoria aerogel. The aerogel microstructure is composed of spherical primary particles with features in the $5-20 \mathrm{~nm}$ range. These particles are connected to one another to form the larger clusters. The microstructure of the $\mathrm{ThO}_{2}$ aerogel is quite similar to other metal oxide aerogels prepared using epoxides as gel initiators. The composition of these clusters was confirmed through the use of energy-filtered (EF) TEM (Figure 2). The EF micrographs clearly show both thorium and oxygen signatures in the aerogel clusters. Examination of the higher magnification micrograph reveals that the $\mathrm{ThO}_{2}$ aerogel is highly crystalline, as evidenced by the lattice fringes seen in the primary particles (Figure 3). Thorium dioxide exists in only one stable crystalline form, a cubic phase with the fluorite structure (Fm3m space group) [21] and, therefore, no detailed structural investigation by X-ray diffraction has been undertaken for the $\mathrm{ThO}_{2}$ aerogels. 
The surface area, pore volume and average pore diameter for the thoria aerogels were measured using nitrogen adsorption/desorption techniques. The material exhibited a surface area $\left(120 \mathrm{~m}^{2} / \mathrm{g}\right)$ that was an order of magnitude higher than those reported for thoria gels prepared using traditional sol-gel methods. The $\mathrm{ThO}_{2}$ aerogel possessed pore diameters in the micro and mesoporic $(2-20 \mathrm{~nm})$ region with an average pore diameter of $21 \mathrm{~nm}$ and pore volume of $0.8 \mathrm{ml} / \mathrm{g}$. These values are comparable to other metal oxide aerogels prepared using propylene oxide as a gel initiator [17-19]. The $\mathrm{ThO}_{2}$ aerogel exhibited an adsorption isotherm of type IV with hysteresis $\mathrm{H} 1$, consistent with a network structure of spherical primary particles (Figure 4) [22]. The isotherm also shows a hysteresis loop at higher relative pressures, a feature that is typically associated with capillary condensation within mesopores, indicating that textural mesoporosity exists within the aerogel framework. These results are also in agreement with the microstructure observed in transmission electron micrographs.

\section{Discussion}

As we have previously shown with main group and transition metal oxides, propylene oxide can be used as a gelation initiator for the preparation of metal oxide aerogels. Metal cations tend to act as acids when solvated in water. Charge transfer from the coordinated water molecule to the empty orbitals of the metal ion causes the positive partial charge on hydrogen to increase, making the coordinated water more acidic. The epoxide acts as an acid scavenger [23] in the sol-gel polymerization reaction, driving the hydrolysis and condensation of the hydrated metal species. The slow increase in the $\mathrm{pH}$ of the solution allows the uniform formation of dimers and then oligomers, which link together through olation and oxolation to give a sol of metal oxide particles 
that subsequently cross-link to afford a monolithic gel. The propylene oxide is ultimately consumed in the gelation reaction, presumably generating ring-opened by-products.

In the case of thorium, the hydrated $\mathrm{Th}^{4+}$ ion is relatively acidic $(\mathrm{pKa} \sim 3.2,[24])$ and, as a result, should be capable of protonating the oxygen of the epoxide ring, leading to a productive ring-opening reaction that slowly and homogeneously raises the $\mathrm{pH}$ of the reaction solution. Initial attempts to prepare thoria alcogels using only propylene oxide as an initiator, however, were unsuccessful. The addition of one molar equivalent of ammonium hydroxide was required to initiate the hydrolysis of the solvated $\mathrm{Th}^{4+}$ ion. One possible explanation for this observation may be related to the fact that the $\mathrm{Th}^{4+}$ ion is the tetravalent metal cation most resistant to hydrolysis [25] and, as such, a stronger base, like ammonium hydroxide, was necessary to initiate sol-gel polymerization reaction. Alternatively, the hydrated thorium ion may be catalyzing a competing "nonproductive" reaction that consumes the propylene oxide without an overall increase in the $\mathrm{pH}$ of the reaction solution. In either case, treatment of the hydrated thorium nitrate solution with ammonium hydroxide and propylene oxide allows for the formation of lowdensity monolithic thoria gels.

The HRTEM results indicate that the thoria gels are nanostructured materials, comprised of particles with diameters in the range of 5 to $20 \mathrm{~nm}$. One of the interesting observations from the HRTEM characterization was that the primary particles of the aerogels are crystalline. The ability to prepare thoria aerogels that are comprised of nanocrystallites may be important for a number of applications. According to the nitrogen adsorption/desorption analyses, the thoria aerogels produced by this method are mesoporous solids with relatively high surface areas. These results are consistent with 
the BET surface area data obtained for the transition metal oxide aerogels also prepared by the epoxide method. In addition, the surface areas for the thoria aerogels are an order of magnitude higher than those reported for thoria materials prepared by traditional methods. Since catalyst efficiency is related to accessibility of the substrate to catalytic sites, the high surface area and mesoporosity of the thoria aerogel might exhibit improved or unique catalytic activity. As mentioned above, metal oxides of the actinide elements have been identified as promising catalytic materials for a variety of organic transformation due to their electrophilic nature and their ability to attain high coordination numbers. The procedure presented here allows for the preparation of highsurface area nanocrystalline thoria materials that may have a significant impact on the use of actinides in catalysis.

\section{Conclusions}

In this report, we describe a straightforward sol-gel method for the preparation of low-density thoria aerogels using both ammonium hydroxide and propylene oxide as the gelation initiators. The monolithic thoria aerogel is comprised of crystalline primary particles with features in the 5-20 nm range. The $\mathrm{ThO}_{2}$ aerogel possesses high surface area and pore diameters in the micro- and mesoporous range. The work presented here, along with our previous work on low-density $\mathrm{UO}_{3}$ aerogels, demonstrates that this technique is general and can be applied to the other actinide elements as well.

Acknowledgements. Work was performed under the auspices of the U.S. Department of Energy by Lawrence Livermore National Laboratory under contract number W-7405ENG-48. 


\section{References}

[1] G. Curran, Y. Sevestre, W. Rattray, P. Allen, K, R. Czerwinski J. Nucl. Mater. 323 (2003) 41.

[2] K. Ananthasivan, S. Anthonysamy, C. Sudha, A. L. E. Terrance, P. R. Vasudeva Rao J. Nucl. Mater. 300 (2002) 217.

[3] S. Dash. A. Singh, P. K. Ajikumar, H. Subramanian, M. Rajalakshmi, A. K. Tyagi, A. K. Arora, S. V. Narasimham, B. Raj J. Nucl. Mater. 303 (2002) 156.

[4] K. Ananthasivan, S. Anthonysamy, A. Singh, P. R. Vasudeva Rao J. Nnucl. Mater. $306(2002) 1$.

[5] R. D. Purohit, S. Saha, A. K. Tyagi J. Nucl. Mater. 288 (2001) 7.

[6] V. R. Choudhary, A. G. Gaikwad, S. D. Sansare Catal. Lett. 83 (2002) 235.

[7] B. Shi, H. A. Dabbagh, B. H. Davis Topics in Catal. 18 (2002) 259.

[8] R. Tismaneanu, B. Ray, R. Khalfin, R. Semiat, M. S. Eisen, J. Mol. Catal. A 171 (2001) 229.

[9] S. W. Ho J. Catal. 175 (1998) 139.

[10] F. Z. Wang, F. ZhuGe, H. Zhang, B. J. Ding Mater. Res. Bull. 38 (2003) 629.

[11] F. Zhuge, Z. Ye, F. Wang, Y. Wang, H. Zhang, B. Ding Mater. Lett. 57 (2003) 2776.

[12] I. C. Cosentino, R. Muccillo Mater. Lett. 32 (19997) 295.

[13] R. D. Purohit, S. Saha, A. K. Tyagi J. Nucl. Mater. 323 (2003) 36.

[14] R. S. Niranjan, M. S. Londhe, A. B. Mandale, S. R. Sainkar, L. S. Prabhumirashi, K. Vijayamohanan, I. S. Mulla Sens. Actuators B 87 (2002) 406. 
[15] C. J. Brinker, G. W. Scherer, Sol-Gel Science, Academic Press, Boston, 1990.

[16] For a recent review, see: T. F. Baumann, A. E. Gash, G. A. Fox, J. H. Satcher, L. W. Hrubesh in: Handbook of Porous Solids, eds. F. Schüth, K. Sing, J. Weitkamp, WileyVCH: Weinheim, 2002, p. 1581.

[17] A. E. Gash, T. M. Tillotson, J. H. Satcher, L. W. Hrubesh, R. L. Simpson J. NonCryst. Solids 285 (2001) 22.

[18] A. E. Gash, T. M. Tillotson, J. H. Satcher, J. F. Poco, L. W. Hrubesh, R. L. Simpson Chem. Mater. 13 (2001) 999.

[19] R. A. Reibold, J. F. Poco, T. F. Baumann, R. L. Simpson, J. H. Satcher J. NonCryst. Solids 319 (2003) 241.

[20] S. J. Gregg, K. S. W. Sing Adsorption, Surface Area and Porosity, $2^{\text {nd }}$ ed., Academic Press, London, 1982.

[21] C. Keller, in: Comprehensive Inorganic Chemistry, Volume 5, eds J. C. Bailar, H. J. Emeleus, R. Nyholm, A. F. Trotman-Dickenson, Pergamon Press, New York, 1975, p. 221.

[22] F. Rouquerol, J. Rouquerol, K. Sing Adsorption by Powders and Porous Solids: Principles, Methodology and Applications, Academic Press: London, 1999.

[23] B. Dobinson, W. Hofmann, B. P. Stark, The Determination of Epoxides, Permagon Press, Oxford, 1969.

[24] C. F. Baes, R. E. Mesmer The Hydrolysis of Cations, John Wiley \& Sons, New York, 1976, p. 160.

[25] D. L. Clark, D. E. Hobart, M. P. Neu Chem. Rev. 95 (1995) 25. 
Figure 1. Transmission electron micrographs of the thoria aerogel at different magnifications.
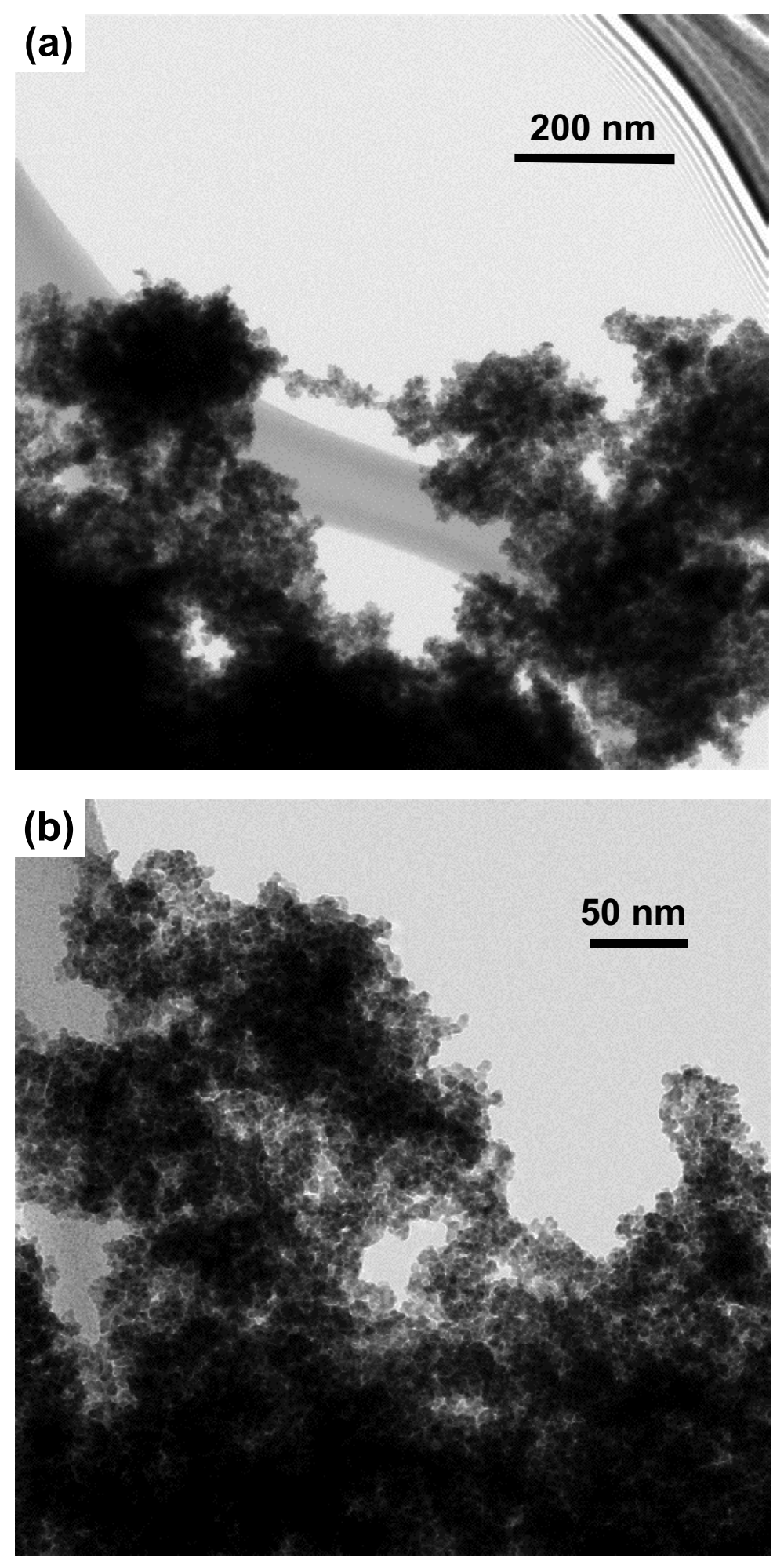
Figure 2. Energy-filtered transmission electron micrographs of the thoria aerogel (a) showing both the thorium (b) and oxygen (c) signatures

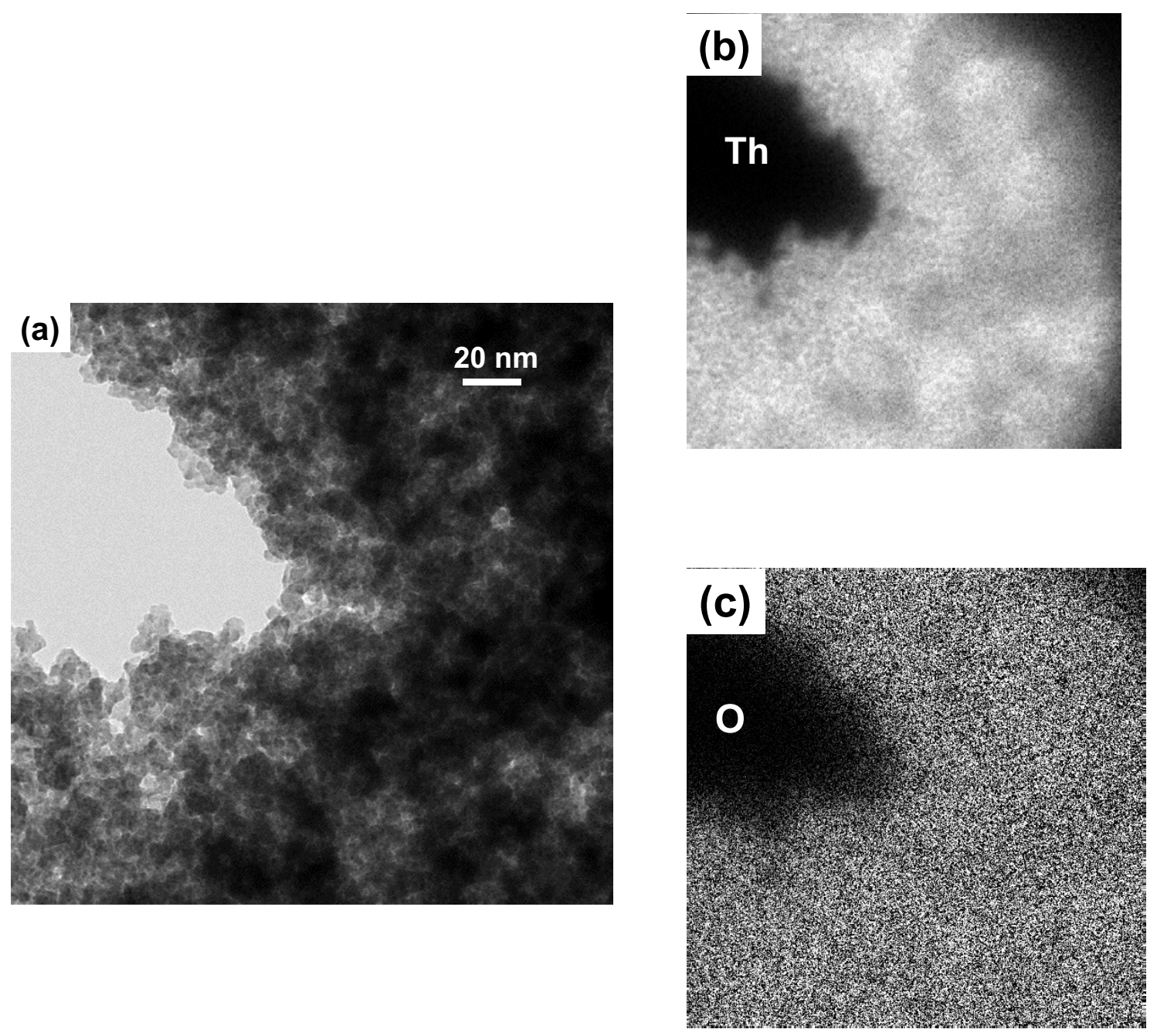


Figure 3. High magnification TEM images showing the lattice fringes of the crystalline thoria particles.

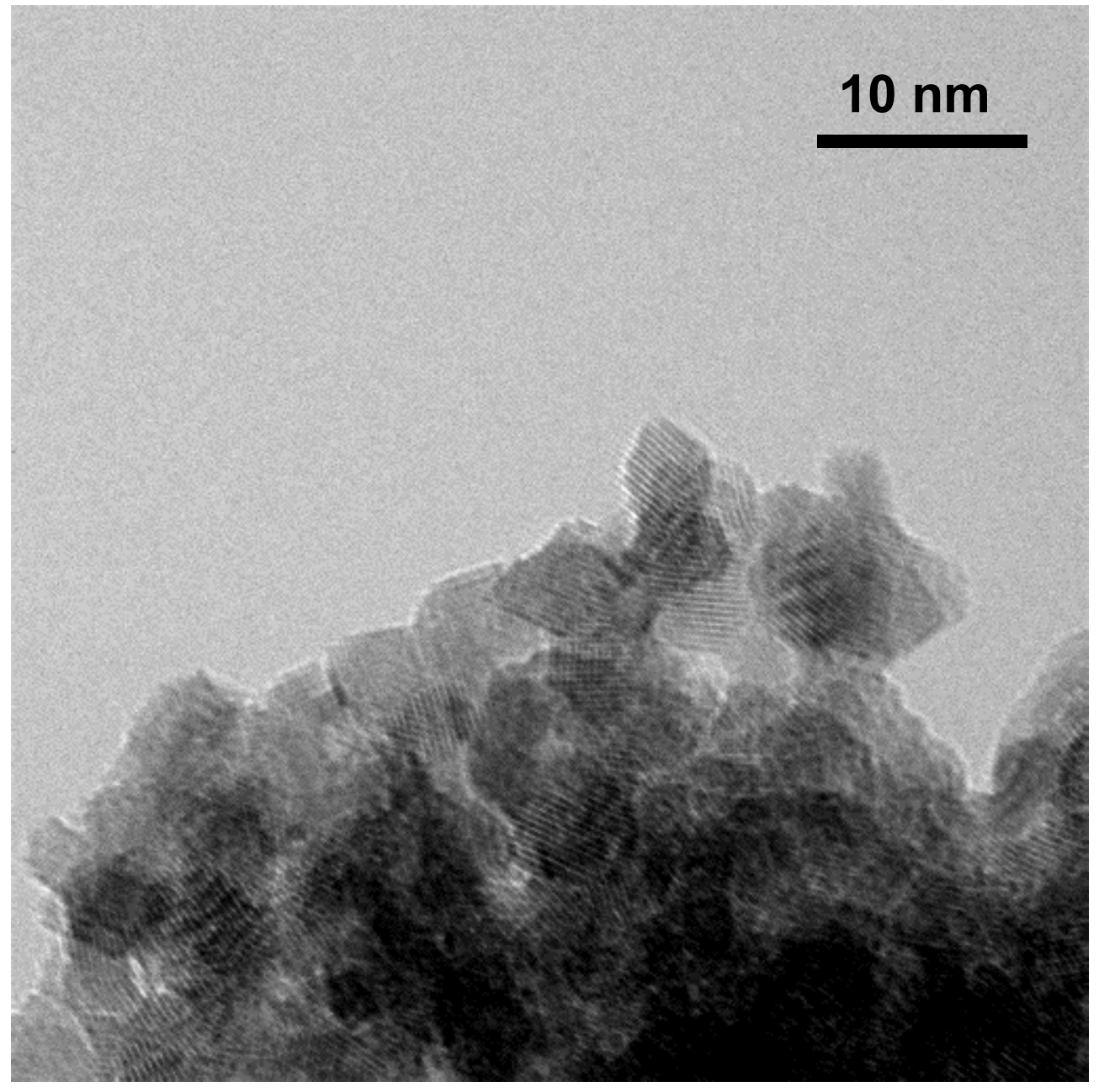


Figure 4. Nitrogen adsorption/desorption isotherm for the nanocrystalline thoria aerogel.

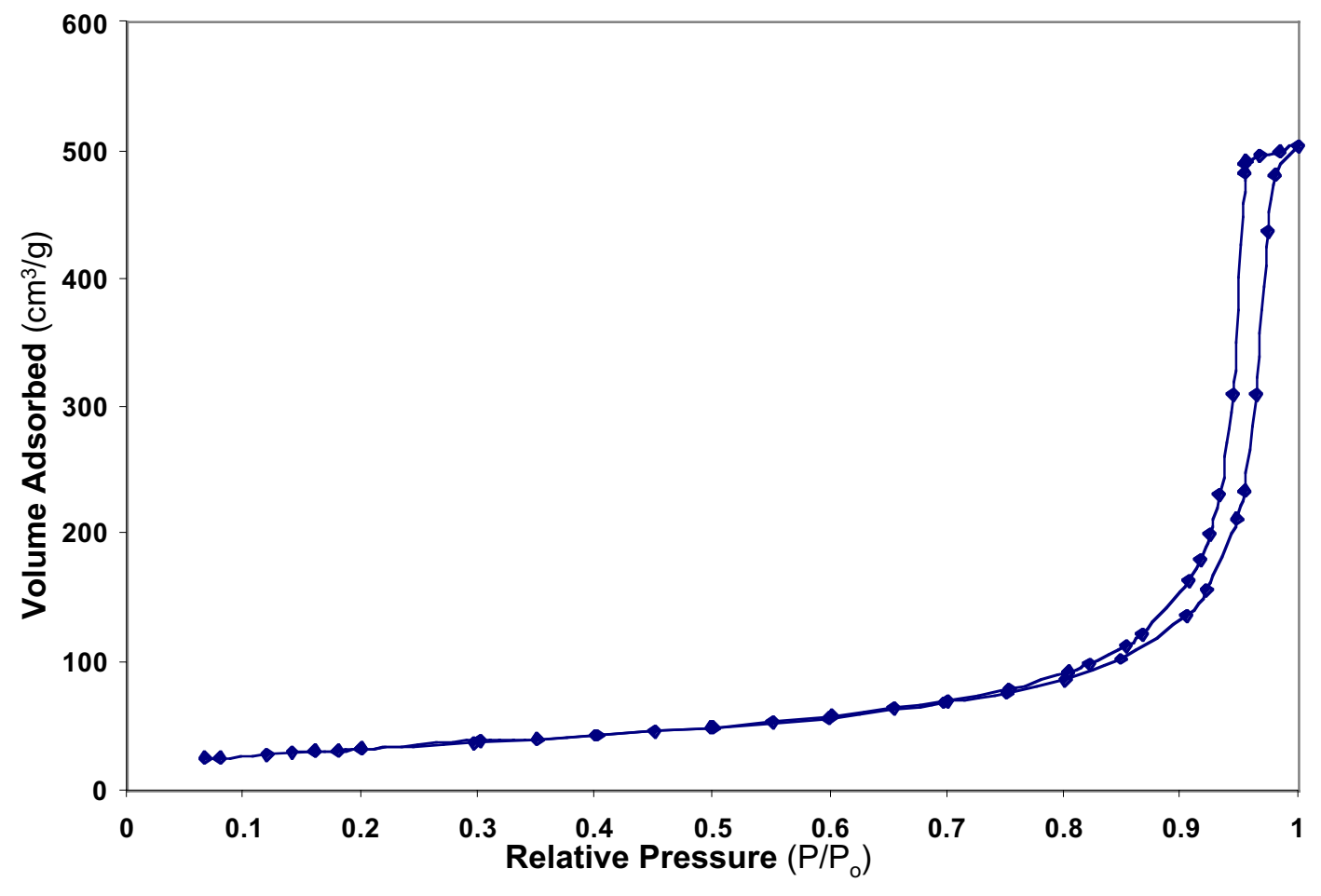

